\title{
Arte Moderna, Trabalho e Resgate Humanístico do Cotidiano na Capela do Cristo Operário: São Paulo, 1951-1967*
}

\author{
Mauro Claro \\ Maria Irene Szmerecsanyi
}

Artista plástico e mestrando da FAUUSP

Professora Doutora de Fundamentos Sociais da Arquitetura de Teoria do Conhecimento e de Metodologia Cientffica aplicadas à Arquitetura e ao Urbanismo
Resumo

Através da Capela do Cristo Operário, este trabalho analisa uma tentativa de organização de trabalhadores fabrís na periferia de São Paulo na década de 50. 0 projeto de ação social sediado na Capela instaurou-se em relação a três parâmetros: ao padrão estético do modernismo; à base política da auto-gestão da empresa capitalista; ao padrão moral do catolicismo na sua vertente socialhumanística do $2^{\circ}$ pós-guerra.

As possibilidades abertas, para uma pesquisa acadêmica, pela inclusão direta e explícita da consideração estética num projeto social vão no sentido de ressaltar a importância das utopias do modernismo para a transformação do ambiente social.

\footnotetext{
Abstract

This paper analyses an attempt of improvement of manual workers' life by means of mobilisation of their aesthetic sense. The doctrinary work was based on three main points: the formation of aes thetic patterns founded on modernism; the self-gestionary management of a capitalist enterprise; the transmission of catholic moral patterns according to the social humanistic interpretation current soon after the 2 nd world war.
}

This appropriation of aesthetic means by a social project makes clear the utopic dimension inherents to the modern movement in the arts. 
Foto 1

Mural Cristo Operário, de Alfredo Volpi, pintado em 1951 no altar da capela. Foto de autoria de Antonio Pirozzelli, publicada no jornal Folha da Manhã em 25/nov./1951 como ilustraçāo para texto de Leonardo Arroyo intitulado Capela do Cristo Operário - o reino do céu entre os homens (Folha da Manhã, São Paulo, 25/nov./1951. Caderno Atualidades e Comentários, p.5).

\section{Introdução}

O trabalho pretende analisar a experiência de ação comunitária da Capela do Cristo Operário considerando-a como tentativa de organização do cotidiano de trabalhadores fabrís e moradores de um bairro popular na cidade de São Paulo na década de 50 .

O projeto da capela foi liderado por um padre dominicano que trouxera, de sua experiência como padre e operário na França na década de 30 e de sua militância no movimento Economia e Humanismo, a visão de um trabalho que unisse a reflexão sobre uma doutrina moral com a prática do dia-a-dia. Economia e Humanismo constituíram uma doutrina social cristã surgida na igreja católica como alternativa à polaridade Comunismo versus Capitalismo estabelecida após a II Guerra Mundial durante os primeiros anos da Guerra Fria.

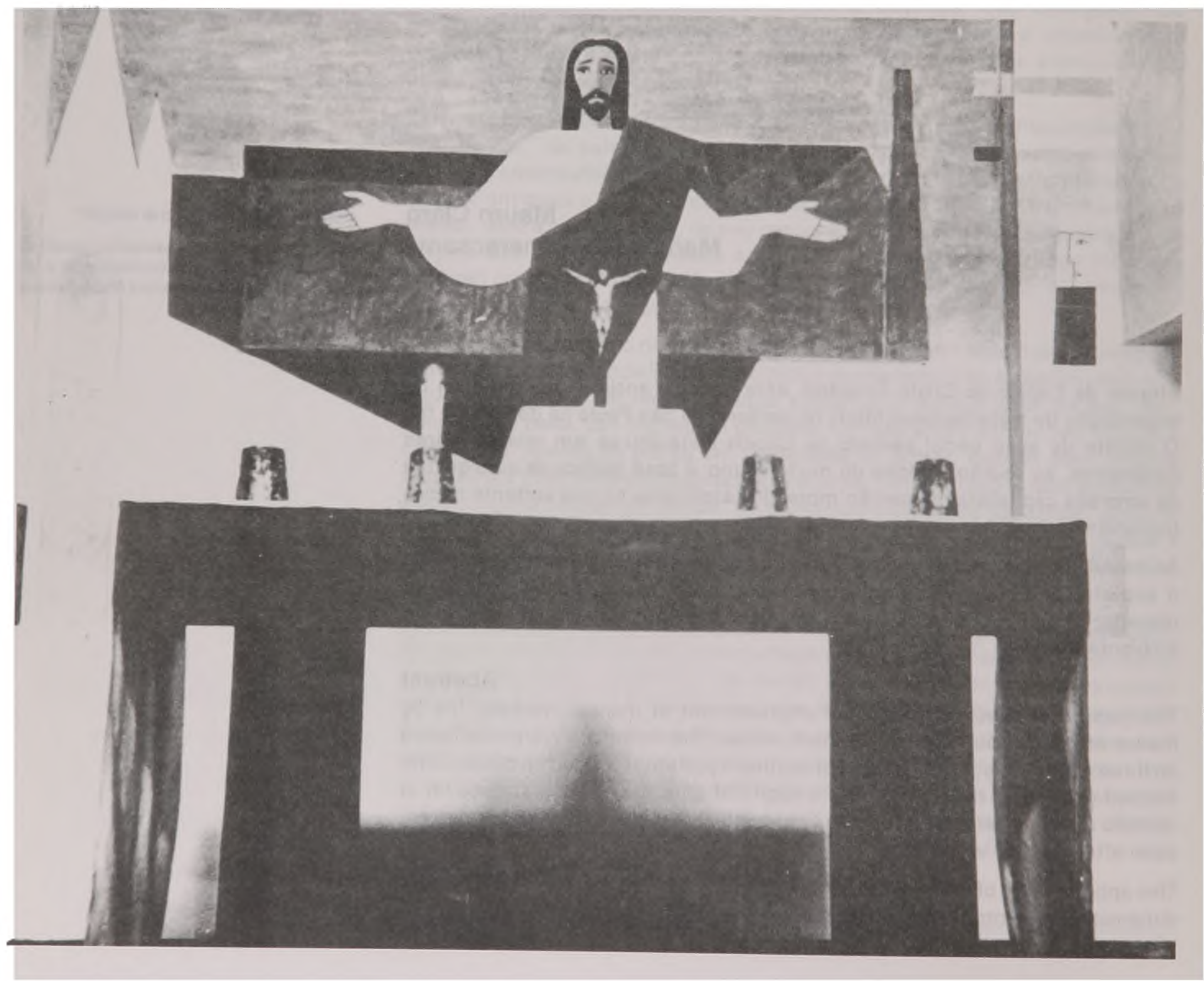


O movimento foi "inspirado e dirigido internacionalmente pelo padre L. J. Lebret" (Lamparelli, 1993) que em 1947 fundou em São Paulo um instituto de consultoria e planejamento, SAGMACS, ao qual coube a elaboração de projeto de planejamento territorial dessa cidade na década de 50 (interrompido na gestão Adhemar de Barros na prefeitura paulistana).

Esse projeto de ação comunitária e a capela que o sediou contaram na sua formação (1951-54) e durante todo o período de efetivação (1951-67) com o trabalho continuado de uma plêiade de artistas plásticos, arquitetos e intelectuais que se juntaram a essa direção religiosa-católica sob os pressupostos estéticos do modernismo. As razōes que motivaram tal cooperação dessa elite cultural estão sendo objeto de investigação, sendo provável que estivessem permeadas por motivos políticos de mobilização da classe operária.

A idéia da capela constitui-se como projeto de futuro que pudesse questionar e elaborar as relações de classe no cotidiano, entendido como campo de embate da consciência e da prática. Assim, os elementos presentes no projeto de ação da capela centram-se em:

a. O enfrentamento das insuficiências materiais da vida do operariado (funda-se uma empresa fabricante de móveis);

b. o exercício crítico da administração dessa produção (autogestão e inserção do produto no mercado);

c. a experiência estética direta através do contato com obras e artistas (teatro, cinema, artes plásticas);

d. a instrumentalização do conhecimento técnico e estético, numa experiência educacional inserida no próprio processo de produção (ensino de técnicas de trabalho e de história da arte).

O relato desses aspectos, que faremos no decorrer deste trabalho, baseia-se em informações obtidas em pesquisa efetuada em 1992-93 a partir de entrevistas com pessoas que participaram do processo ou que com estas tiveram contatos, além de consulta a periódicos, principalmente jornais.

Uma vez identificadas as pertinências desse projeto com relação às esferas de ação tanto estética quanto moral (política e religiosa) e também com relação às suas implicaçōes educacionais (catequese religiosa e estética combinada com a instrumentalização da força de trabalho operária), o trabalho pretende elaborar uma colocação do problema para a contemporaneidade, usando para isso o conceito marxista de trabalho alienado. Também será considerado seu significado enquanto experiência moldada dentro dos limites da racionalidade modernizante e que encontra seus limites exatamente na superação histórica da modernidade.

\section{Frei João Batista, os Padres Operários e "Economia e Humanismo"}

O movimento dos padres operários surge em 1943 e desenvolve-se na França do pós-guerra como reconhecimento, por um setor da igreja católica, da necessidade de incorporar as colônias de trabalhadores manuais (portuários e operários em geral) frente às tensōes geradas pela guerra e o fortalecimento de partidos de esquerda, entre os quais o PCF.

Essa tentativa pode ser vista como experiência que ultrapassa o mero exercício do controle ideológico ou político. Constitui-se como trabalho pedagógico com características realmente missionárias uma vez que os padres viviam e 
trabalhavam junto aos operários partilhando seu modo de vida e tirando daí o conhecimento das reais necessidades materiais, intelectuais e emocionais de seus companheiros. Além disso procuravam, nesse convívio, evidenciar as possibilidades de compatibilizar a vida cristã com as contradições de um cotidiano penoso em termos materiais, dada a carga de trabalho e a precariedade do consumo, superando o empobrecimento espiritual daí conseqüente.

O entendimento, por parte da linha dominante da igreja católica, de que a proximidade dos padres operários com grupos sindicais de inspiração marxista representava uma ameaça de contágio resultou no seu banimento em 1954: os padres deveriam abandonar toda função sindical e voltar "para casa" Tal proibição não conseguiu encerrar a experiência dos padres operários: muitos recusaram a ordem de Roma e mantiveram-se nas fábricas.

É importante ressaltar que tanto os padres operários como Economia e Humanismo, movimento que frei João Batista conheceu de perto, iniciaram na França do pós-guerra e se disseminaram mundialmente a partir daí. Há indicações que nos permitem supor possuírem ambos uma origem comum, a Juventude Operária Católica, mas esta é ainda uma hipótese a ser checada.

Frei João Batista, nascido em São Paulo em 1913, ordena-se padre na França em 1938 , onde trabalha numa fábrica de relógios. Em 1948 passa alguns meses em Grenoble onde participa de uma reunião do movimento Economia e Humanismo, fundado em 1941-42 pelo padre Lebret.

Em 1950, já de volta ao Brasil, é convidado a dirigir o trabalho religioso na vila Brasílio Machado, trabalho esse iniciado havia já cerca de 8 anos por uma entidade operária católica chamada Círculo Operário do Ipiranga - da qual falaremos adiante. É necessário notar que a vila Brasílio Machado, situada no bairro do Alto do Ipiranga fazia parte, naquela época, da periferia da cidade.

Acolhido pela comunidade local como alguém que poderia enfim conduzir a construção da igreja de Santo Antônio, em substituição à exígüa capela que havia no lugar, frei João Batista se propôs a formar uma "comunidade de trabalho" e não a construir uma igreja, idéia que surgira-lhe na França quando de seu contato com Economia e Humanismo. Nesse período conhecera a experiência autogestionária de duas comunidades operárias: Boimondau e Atarfrance.

Frei João iniciou em 1950 sua atividade na vila pela reconsagração ao Cristo Operário da capela existente, dedicada a Santo Antônio e que funcionava num antigo armazém. A reforma do mesmo, feita a partir de desenho de seu próprio punho é a que deu à capela sua forma atual, reconhecida de imediato como de valor arquitetônico pela autoridade do arquiteto Rino Levi.

\section{Frei João Batista e o Museu de Arte Moderna de São Paulo}

Nesse mesmo período começa a funcionar o Museu de Arte Moderna de São Paulo (MAM), fundado em 1948 pelo industrial Francisco Matarazzo Sobrinho líder de sua classe e nome emblemático já que pertencente a uma das famílias mais destacadas em termos do desenvolvimento da indústria paulista.

O MAM reunia um conjunto de intelectuais participantes de sua direção e das atividades ali promovidas. Entre eles podemos citar o próprio Rino Levi e seu amigo o prof. José Petronillo de Santa Cruz (então frei Benevenuto de Santa Cruz), o pintor Alfredo Volpi e Lourival Gomes Machado, crítico de arte, diretor 
do Museu, professor de Política na Faculdade de Filosofia da USP e mais tarde diretor da Faculdade de Arquitetura e Urbanismo da mesma universidade.

Frei Benevenuto, sendo dominicano, ordem de pregadores e voltada intensamente para o trabalho intelectual, se ligava a frei João Batista e à capela, ali celebrando missas e se interessando pelo trabalho de catequese.

Depois da fase pioneira da Semana de Arte de 22 e com a crescente atenção dedicada a partir da década de 30 à sistematização museológica, com o início da ação preservacionista do Estado pela criação do Serviço do Patrimônio Histórico e Artístico Nacional, com a formação dos clubes de artistas modernos e das familias artísticas, com a revolução modernizante nos salões de artes plásticas, com, enfim, a maioridade do moderno (Lourenço, 1990) - a criação do MAM e do MASP em 1947 e 1949 representa o momento em que a visualidade moderna, ligada à idéia de progresso e cosmopolitismo, se estabelecia como hegemônica no país, tendo inclusive se associado diretamente à construção da imagem do estado varguista como promotor da cultura nacional.

A relação entre frei João Batista e os grupos intelectuais do MAM pode ser mostrada pela decoração da capela. Nela estão três painéis de Volpi, três da pintora Yolanda Mohalyi, um de Giuliana Segre Giorgi, além de esculturas de Moussia Pinto Alves, objetos de Robert Tatin e Giandomenicco de Marchis, luminárias de Elizabeth Nobiling, jardins do arquiteto Roberto Burle-Marx, um vitral do artista/designer Geraldo de Barros e outros quatro de Alfredo Volpi.

\section{A Cidade de São Paulo como Centro Industrial e Operário}

A industrialização em São Paulo, iniciada no final do século 19 e intensificada nas duas primeiras décadas do 20 , não é abalada pela decadência do comércio cafeeiro a partir de 1929. Até ao contrário: devido à diversidade de origem

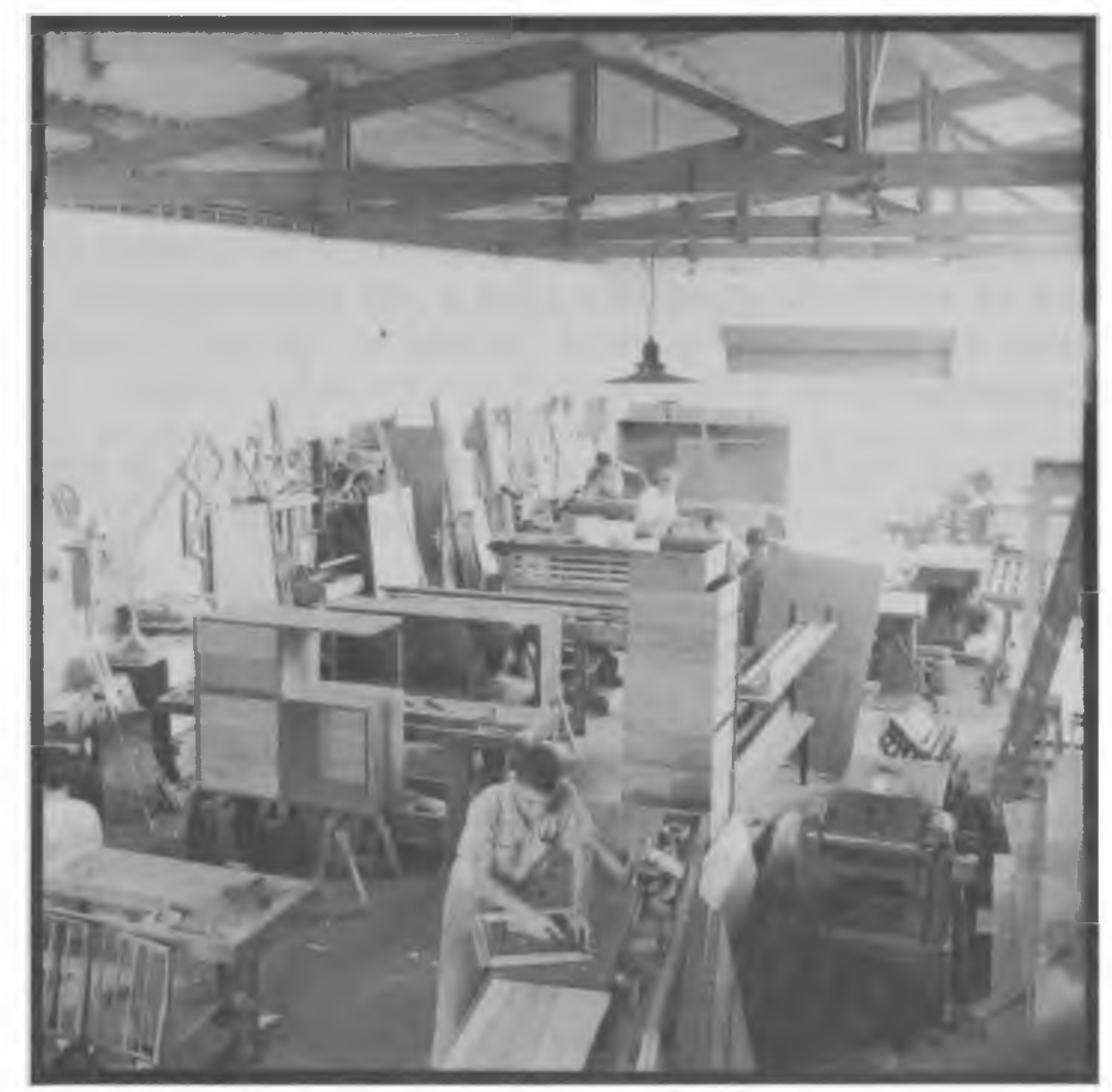

Foto 2

Oficina de produção da Unilabor, situada ao lado do edificio da capela. Foto do arquivo de Geraldo de Barros. (c. 1954). 
dos capitais que formavam a indústria paulista, esta pôde se adaptar e crescer durante a Segunda Guerra com a substituição de importações e o amparo do Estado (Szmrecsanyi, 1993).

Nessa fase, e até 1950 de modo genérico, a indústria paulista diversifica sua produção de bens de consumo imediato e começa a desenvolver a indústria de base. De 50 a 60, principalmente nos anos J. K., são promovidas as indústrias de consumo durável, incluindo a automotriz. Nessa década e na seguinte, o Estado de São Paulo concentra cerca de $60 \%$ do valor da produção do país enquanto a cidade de São Paulo, com sua área metropolitana, responde por $87,4 \%$ dessa parcela (Szmrecsanyi, 1993).

A predominância do imigrante europeu na formação da classe operária se relativiza desde 1930 , com o acolhimento de um crescente contingente de trabalhadores nacionais expulsos do campo. Diferentemente do operário europeu, tecnica e politicamente já formado, o trabalhador brasileiro de origem rural precisa ser disciplinado como um trabalhador fabril.

Pode-se dizer que a passagem para o meio urbano significa, para esta parcela do operariado nacional, a educação através do emprego: formação profissional, acesso aos benefícios previdenciários, educação para os filhos, possibilidade de poupança e casa própria e, nesse sentido, a integração dentro do projeto burguês. A proletarização em São Paulo representa uma melhoria na vida do homem rural. Atenua-se, assim, por parte deste novo setor do operariado urbano, a oposição ao domínio patronal e ao sistema produtivo. Do ponto de vista do trabalhador, um projeto de ascensão social dentro dos limites dos interesses da burguesia parecia bastante viável dada a prosperidade do sis tema e a distribuição de vantagens a diferentes classes, muito embora marcada pela desigualdade.

Este panorama de relações de classe no início da década de 50 acentua-se pelo populismo dos políticos e governantes, que perdurou até 1964. Assim, pôde ser criada e mantida a ilusão de uma convergência possível de interesses de classe, como um projeto de desenvolvimento nacional harmônico.

\section{A Capela, a Industrialização e o Círculo Operário do Ipiranga}

"O mapa da Sara Brasil, de 1930, mostra o colar quase contínuo de indústrias que se estabelecem entre a Lapa e um pouco além da estação do Ipiranga. Além de indústrias, grandes armazéns também optaram por este sítio." (Langenbuch,1971).

O Ipiranga industrializa-se a partir de 1890 . Em 1934 já possuía um conjunto de indústrias de porte (entre outras: Tecelagem Jafet, 1906; Linhas Corrente, 1907; Tecelagem Artex, 1924; General Motors, 1925) e uma população de 40.825 habitantes, tendo crescido 3,4 vezes desde 1920 quando tinha 12.064 habitantes. Esse crescimento continuou acelerado até o final da década de 50, estabilizandose a partir de então. Em 1960 o bairro tinha 156 mil habitantes. Assim, em 40 anos cresceria mais que dez vezes, num ritmo muito maior que o do município, o qual passara de 580 a 3.602 mil no mesmo período (PMSP, 1988).

Nesta área predominantemente operária cria-se em 1936 o Círculo Operário do Ipiranga (COI), entidade católica caracterizada por Aziz Simão (Simão, 1966) como sendo típica do circulismo operário, forma de associacionismo implantada no Brasil desde a década de 30 . Essas associações têm caráter assisten- 
cial, anticomunista militante e conciliatório em termos de classes e obtêm apoio decidido do getulismo, sendo inclusive elevadas pela lei trabalhista, em 1941, à condição de órgãos técnicos e de consulta do Ministério do Trabalho (Martins, 1979).

Em 1942 (senão antes) o COl funda um núcleo de atividades na vila Brasílio Machado, o qual prospera até que, em 1950, a propriedade e os imóveis a ele pertencentes são vendidos à Ordem dos Dominicanos. Nessa mesma oportunidade, frei João Batista assume a direção dos trabalhos religiosos e encerra a atuação do COI na vila.

\section{A Atuação de Frei João Batista}

\section{O Projeto}

O COI foi com presteza substituído pelo projeto de atuação abraçado por frei João Batista. Tratava-se de organizar uma comunidade vinculada por uma experiência de trabalho autodirigida e que não se reduzisse à experiência artesanal, promovendo um exemplo de produção fabril não espoliativa e preservadora de valores espirituais do trabalhador. O projeto procurava ir bem além da organização de uma atividade econômica, pois pretendia instaurar um convívio que incluísse a família não só como membros freqüentadores da capela, mas como âmbito social dos problemas a serem partilhados e resolvidos pela comunidade.

Reportando-se à Encíclica Rerum Novarume, mais particularmente, à redefinição mais radical de João XXIII na Encíclica Mater et Magistra quanto à doutrina social católica, busca-se a justiça social encarada não apenas como resultado da justa distribuição dos frutos do trabalho, mas considerando o próprio processo produtivo como fundamento do equilíbrio espiritual do indivíduo e da sociedade.

Nessa perspectiva, coloca-se como objetivo maior a atribuição de responsabilidades de gestão ao trabalhador manual: responsabilidade e liberdade, vistas como partes da dignidade humana deveriam ser resgatadas ante as formas de subordinação do trabalho no capitalismo, apresentando-se como alternativa a este e simultaneamente ao materialismo em vigor nos países socialistas. A idéia da propriedade privada, no entanto, era preservada quase como fundamento da liberdade, como entre os pensadores burgueses e liberais, com a diferença de pretender estendê-la a todas as classes.

Citando João XXIII, frei João Batista em seu livro Unilabor, uma revolução na estrutura da empresa, explica: "De nenhum modo pretende a Igreja defender a atual ordem de coisas, como se nela reconhecesse a expressão da vontade divina, nem assume o patrocínio dos opulentos e dos ricaços, desprezando o direito dos pobres e dos indigentes. O que ela entende ensinar é que a propriedade particular constitui uma garantia da liberdade da pessoa humana, intervindo ao mesmo tempo como elemento indispensável no estabelecimento de uma justa ordem social"

A concepção de frei João Batista é a de que se passava rapidamente de uma civilização do capital para uma civilização do trabalho, superando o liberalismo econômico e atribuindo aos operários partes ativas nos negócios das empresas particulares ou do Estado constituindo, estas, formas de comunidade humana (p. 9, op. cit.). 
Foto 3

Mesa fixa em ferro com tampo de fórmica branca e cadeira em ferro e estofada, ambas para sala de refeiçāo, produzidas pela Unilabor. Projeto de Geraldo de Barros. Foto do arquivo de Geraldo de Barros.
A idéia da indústria era criar "um pequeno domínio onde um punhadinho de homens podiam trabalhar e criar, produzir e vender, sem ter que olhar o seu bem pessoal como uma conquista arrancada aos demais: o que é de todos é também de cada um, e o que é de um é a alegria de todos". (p. 29, op. cit.)

\section{A Efetivação}

O centro de efetivação do projeto não foi somente a capela, mas primordialmente uma indústria de móveis sediada no mesmo terreno, na rua Vergueiro, antigo caminho de Santos. Eram seus três sócios fundadores: Justino Cardoso, engenheiro industrial, Geraldo de Barros, artista e bancário e Antonio Thereza, ferramenteiro. O capital foi obtido por empréstimo bancário, o prédio já existia e nele foram colocadas máquinas e gerador de força.

A idéia de produzir móveis foi de Geraldo de Barros a partir de sua experiência em desenhar os móveis de sua própria casa. Procurou-se um marceneiro especializado, achado entre os membros da JOC (Juventude Operária Católica). O primeiro cliente foi Paulo Emílio Salles Gomes, cineasta e professor fundador da ECA (Escola de Comunicaçōes e Artes da USP).

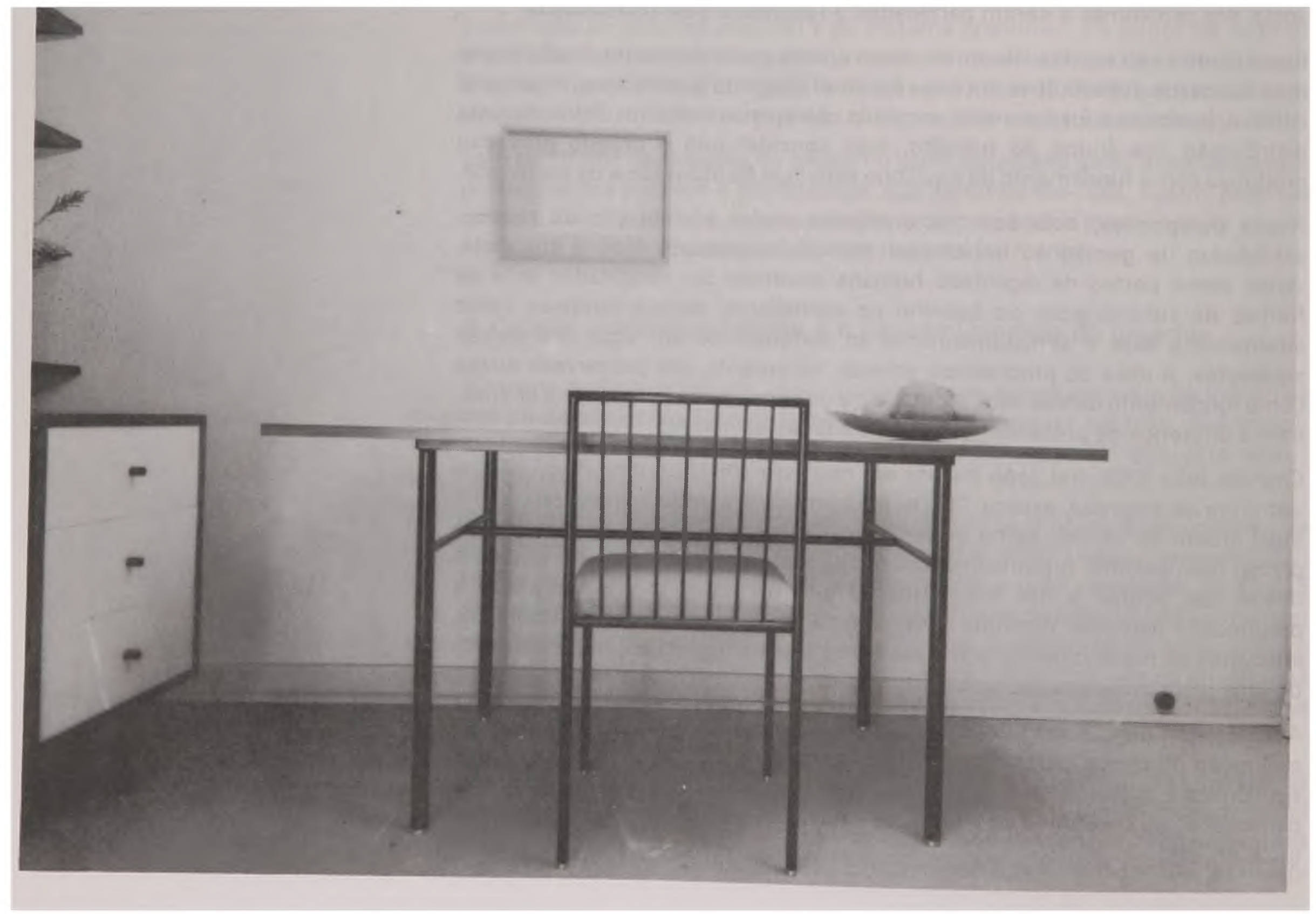


O nome Unilabor expressou o ideal de união no trabalho. O advogado Mário Carvalho de Jesus registrou a empresa como sociedade por cotas de responsabilidade limitada. Foi elaborado um regulamento onde ficava estabelecido que a empresa funcionaria internamente como comunidade de trabalho, fora do regime capitalista, não havendo portanto distinção entre empregado e empregador. Além disso, após 1 ano de trabalho, todo trabalhador teria participação nos lucros e na direção, resguardado o pagamento do empréstimo inicial. O proprietário seria considerado a comunidade, como pessoa constituída de todos os seus membros.

O artigo $8^{\circ}$ estabelecia que o lucro, se existisse, seria dividido em três partes iguais: uma cabendo aos companheiros, outra integrando-se a um fundo de reserva da comunidade e a última aplicada em obras de cultura e aperfeiçoamento humano e social.

Haveria um chefe da comunidade, eleito por maioria absoluta, por um período de 3 anos, podendo ser reeleito. Esse chefe seria responsável pelos resultados e pela escolha dos meios. A assembléia, convocada obrigatoriamente a cada 3 meses, era o órgão soberano.

Esse regulamento tratava também da moral comum aos companheiros, devendo promover como valores mínimos a vida, o homem, a família, a sociedade, o trabalho, o bem comum. Afirma o respeito à individualidade e à opinião e se posiciona contra a transformação do homem em meio para produzir riquezas e não como finalidade última da produção.

Esse estatuto permitiu que a empresa tivesse um andamento contínuo durante a década de 50 .

Mas a ideologia era tão importante dentro da empresa que, por volta de 1960 alguns episódios envolvendo companheiros com militância partidária abalaram o ambiente quando petebistas, anarquistas e trotsquistas questionaram, seja nas reuniōes, seja fora delas, a validade do projeto da empresa.

No entanto, causas econômicas também pesaram uma vez que a indenização cobrada por dois de seus membros quando de seu desligamento foi motivo de abalo para a saúde financeira da empresa por volta de 1961.

O declínio financeiro da empresa agudiza-se a partir de 1964 e não deixou de estar relacionado à perseguição política de muitos dominicanos.

A política de intensa concentração de capital, que levou à falência as empresas de menor porte entre 1964 e 67. chegou a afetar diretamente a Unilabor. Carta de frei João Batista ao presidente Castelo Branco em jornal do Rio no ano de 1965 é evidência nesse sentido (Santos, 1965).

Essa experiência não gerou seguidores imediatos.

\section{Conclusão}

\section{A Questão do Trabalho na Unilabor e a Visão Marxista da Alienação do Trabalho}

A oposição entre a doutrina trabalhista católica e o comunismo enquanto doutrina e política efetiva do pós-guerra não impede que alguns pontos de semelhança 
possam ser percebidos entre essa doutrina católica e a filosofia marxista do trabalho.

A questão da alienação do trabalhador está contida em ambas as concepcões. A concepção de Marx de que a alienação se dá pela separação do homem de seu trabalho, quer enquanto atividade, quer enquanto seu produto, levando a um alheamento e um distanciamento de si mesmo, percorre o ideário posto em prática por frei João Batista e sua comunidade. É da concepção de Marx que o homem sob o sistema capitalista só pode se tornar um trabalhador ao negar-se em suas características propriamente humanas. Assim, sendo o trabalho a atividade que o distingue do animal, pois pelo trabalho é capaz de exercer a criatividade prevendo o produto e projetando o modo de execução, sob o capitalismo o trabalhador não escolhe nem um nem outro. $A$ isso soma-se o fato de não dominar a sua própria pessoa durante o período de trabalho, separa-se de si mesmo pois abdica de comandar sua própria atividade.

Finalmente seu cotidiano de trabalho alienado o conduz, segundo Marx, a expressar-se como ser livre apenas nas funçōes que partilha com os animais. Assim, caracteriza-se a desumanização através do trabalho cotidiano, sob o capitalismo.

\section{A Capela e o Desenvolvimento da Racionalidade Moderna}

No Brasil, a crise da ideologia modernizante vai se revelar ao final da década, com a substituição do governo J. K. e principalmente com o golpe de 64 .

A ação comunitária na capela teve lugar num momento de afirmação do desenvolvimento brasileiro pela consolidação da indústria voltada para o mercado interno, embora aberta ao capital internacional. Além disso, ocorre nesse momento de intensa metropolização da cidade de São Paulo, que aparece em 1960 como a maior cidade brasileira tanto em termos demográficos como em volume de produção e transações econômicas. Frente à ruptura do modelo populista, a partir do golpe de 64 , uma nova ordem se interpôs ao projeto em que se engajavam aquelas vanguardas culturais, mostrando seu caráter utópico, contribuindo para o seu enfraquecimento e levando rapidamente ao seu aniquilamento em 1967

Dessa forma, a história da capela é testemunho de um processo mais amplo de transformação social, política e cultural, numa época em que começam a ruir as crenças num futuro luminoso constituído a partir do império da razão. Momento no qual, para o país, a imagem de São Paulo como metrópole salvadora, idealmente moderna e instrumentalmente modernizadora, sucumbia também.

\section{Bibliografia}

LAMPARELLI, Celso Monteiro. Louis-Joseph Lebretea pesquisa urbano-regional no Brasil. Trabalho apresentado no SEMINÁRIO DE HISTÓRIA DA CIDADE E DO URBANISMO, Salvador/Bahia, abril 1993.

LANGENBUCH, Juergen Richard. A estruturação da Grande Sāo Paulo. Rio de Janeiro: IBGE, 1971.

LOURENÇO, Maria Cecília França. Operários da Modernidade: - anos 30/40. São Paulo: Hucitec - Edusp, no prelo, 1990.

MARTINS, Heloísa Helena Teixeira de Souza. Igreja e movimento operário no ABC, 1954-1975. São Paulo; Hucitec. Prefeitura de São Caetano do Sul, 1994 
MARX, Karl. Estranged labour (excerto de manuscritos econômicos e filosóficos de 1844). In: WRIGHT Mills, C. (org.). Images of man - the classic tradition in sociological thinking. New York: Braziller, 1962. p. 496-507.

SÃo PAULO (cidade) (Prefeitura Municipal de São Paulo). História e caracterização da área regional do Ipiranga. São Paulo: PMSP, 1988. 2v.

SANTOS, João Batista Pereira dos. Unilabor, uma revolução na estrutura da empresa. São Paulo: Duas Cidades, 1962.

Diga não, Presidente! Jornal Última Hora, 24 jun. 1965.

SIMĀO, Aziz. Sindicato e estado: suas relaçōes na formação do proletariado em São Paulo. São Paulo: Dominus, 1966.

SZMRECSANYI, Maria Irene. Rio e Sāo Paulo: raízes da substituição da metrópole nacional. REVISTA USP, n. 17, São Paulo, mar./abr./maio 1993, p. 202-219.

\footnotetext{
- O presente trabalho origina-se da pesquisa de mestrado de Mauro Claro, intitulada A comunidade de trabalho Unilabor: modernidade estética como parte da ação de catequese católica num meio operário em São Paulo entre 1951 e 1967, em andamento, sob orientação da Prof` Dr" Maria Irene Szmrecsanyi e co-orientaçāo da Prof" Dr Maria Cecllia França Lourenço, do Depto. de História da Arquitetura e Estética do Projeto da FAUUSP, com apoio do CNPq. Reúne duas contribuições complementares: a escolha da capela e os dados historicos sobre a comunidade analisada são produtos especlficos de Mauro Claro. A vinculação de ambos ao cotidiano, à teoria da alienaçāo e ao humanismo cristāo sāo interpretaçōes de Maria Irene Szmrecsanyi. O texto final resulta de redaçāo discutida por ambos.
} 